\title{
NOVEL COLOURS AND THE CONTENT OF EXPERIENCE
}

\author{
BY
}

\section{FIONA MACPHERSON}

\begin{abstract}
I propose a counterexample to naturalistic representational theories of phenomenal character. The counterexample is generated by experiences of novel colours reported by Crane and Piantanida. I consider various replies that a representationalist might make, including whether novel colours could be possible colours of objects and whether one can account for novel colours as one would account for binary colours or colour mixtures. I argue that none of these strategies is successful and therefore that one cannot fully explain the nature of the phenomenal character of perceptual experiences using a naturalistic conception of representation.
\end{abstract}

\section{Introduction}

In this paper I propose a counterexample to naturalistic representational theories of phenomenal character. The counterexample is generated by experiences of novel colours reported by Crane and Piantanida. I will explain why this counterexample arises and offer a diagnosis of why such potential counterexamples have been over-looked. In light of this I suggest that one cannot fully explain the nature of the phenomenal character of perceptual experiences using a naturalistic conception of representation.

In the first two sections of the paper I explicate the relevant details of representationalism and I briefly outline the theory of colour properties that the representationalist is committed to. In the third and fourth sections I describe the empirical facts and experiments concerning the production of experiences of novel colours and explain why the results of this research are problematic for the representationalist. In section five I consider some replies that a representationalist could make and show that they are inadequate. Finally, I offer a diagnosis of this problem. In 
doing so, I discuss the question of what makes a colour experience an experience of colour.

\section{Representationalism}

Many philosophers today hold a representational theory of phenomenal character. Phenomenal character refers to the distinctive quality that perceptual and sensational experiences seem to have; it is identified with "what it is like" to undergo experiences and sensations. ${ }^{1}$ The central tenet of representationalism is that phenomenal character is identical with the content of experience. Consequently, all aspects of phenomenology are representational and all differences in phenomenal character are differences in what is represented.

One reason to hold this position is that experiences seem to be transparent. ${ }^{2}$ That is, when you introspect and pay attention to the nature of your experience, you just seem to be paying attention to the objects and properties that appear to be in your environment. At no time do you encounter your experience or something that exists in yourself, as opposed to the objects and properties that seem to be around you. This motivates the thought that what your experience is like can be explained by what it is that your experience represents in your environment.

Many representationalists wish to provide a naturalistic explanation of phenomenal character. Indeed, the desire for a naturalistic theory is often what motivates the representational position. ${ }^{3}$ Such representationalists therefore aspire to provide a naturalistic theory representation. Two prominent accounts are given by Michael Tye and Fred Dretske. Tye provides a causal covariation theory. He claims that an experience $\mathrm{E}$ will represent that $\mathrm{P}$ if, in optimal conditions, $\mathrm{E}$ is tokened in a subject if and only if $\mathrm{P}$ and because P. Dretske volunteers a teleological theory of representation. An experience $\mathrm{E}$ will represent that $\mathrm{P}$ if and only if it has the function of providing information about $\mathrm{P}$, which it has gained from its evolutionary history.

\section{The representational account of colour experiences}

Because the proposed counterexample to representational theories concerns colour, I now consider in more detail the representationalists' account of colour.

What are colours? It is common to think that physical objects, which we normally judge to be coloured, have some property in virtue of which they are coloured. We can divide such theories of colour properties into subjective and objective theories. 
A subjective view of colour properties holds that it is essential to, and definitive of, a colour property, say red, that to normal perceivers, in normal conditions, an object that has that property will look red. ${ }^{4}$ One way to bring out the force of this point is to note that a subjective view of colour properties holds that there are a priori links between colour properties and colour experiences. For example, it is a priori that red objects have a disposition to look red. On this view, it is part of the meaning of colour terms that the colours are disposed to look a certain way to observers. ${ }^{5}$

The thought behind subjectivist accounts of colour is that, while properties such as shape are intrinsic properties of objects that can be analysed without reference to perceivers of shape (as geometrical properties), colour properties have to be defined in part by their effects on subjects of experience. There are two prominent subjectivist views. Either a colour property, say red, is a disposition to look red to normal perceivers in standard conditions, or it is the categorical base of such a disposition. ${ }^{6}$

If it were correct, the subjectivist conception of colour properties would undermine the representationalist theory. This is because a representationalist wants to explain the nature of experiences that have the phenomenal character associated with seeing red in terms of experiences that represent red. But if one gives an account of what the property red is in terms of the experiences that it is disposed to cause, one ends up with a vicious circle. This is a well-recognised fact, for example, Tye says:

On the face of it, colours and other 'secondary qualities' (smells, tastes, and sounds, for example) pose a special difficulty for the theory I have been developing. If these qualities are subjective, or defined in part by their phenomenal character, then what it is like to undergo the experiences of such qualities cannot itself be understood in terms of the experiences representing them. That would create an immediate vicious circle. ${ }^{7}$

To illustrate this point, recall that a subjectivist view of colour would be as follows: Experiences of red objects typically have a similar phenomenal character. Call experiences with this phenomenal character $E r$. The property red is the property of objects that disposes them to produce $E r$ experiences (or is the categorical base of such a disposition). The problem arises because the representationalist holds that $E r$ experiences are to be analysed in terms of representation of the property red, and a vicious circle is produced thus:

$\mathrm{Er}$ experiences are those which represent a disposition (or the categorical base of a disposition) to produce $E r$ experiences.

In response to this conclusion, the representationalists reject any view of colour that holds it to be a subjective property. An objectivist view of colour properties is one that does not specify colour properties in terms of experiences. Michael Tye, for example, claims that: 
the colours we see objects and surfaces to have are simply intrinsic, observer-independent properties of those objects and surfaces. ${ }^{8}$

Similarly, Dretske claims:

color is whatever property it is the function of colour vision to detect. The fact that so many different conditions cause us to experience red does not show that what we experience when we experience red is not an objective property. It only shows that which property it is may no longer be obvious from the variety of conditions that cause us to experience it. ${ }^{9}$

How does one go about finding out what these objective properties are if one is an objectivist? The obvious candidates for objective colour properties are the physical properties of objects that science tells us are relevant in colour vision. ${ }^{10}$ Two central tenets of objective physicalist accounts of colour are that colours are identical with certain physical properties of objects and that colour perception consists in the detection of these properties. To find out what property all red objects have in common, objective physicalists will rely on the judgements of many standard perceivers, in specified good conditions, to pick out red objects. Once the red objects are selected, one looks to see what physical property they have in common. William Lycan exemplifies this strategy for identifying physical colour properties. He claims:

my idea is to take as given (1) standard human visual physiology, (2) normal viewing conditions understood in Shepard's way or something like it, and (3) subjects' verbal judgements about the colours of objects. Together, these three factors should in principle yield a reference-fixing triangulation of any given Armstrongian colour property. ${ }^{11}$

Although colour properties are picked out in this way, it is held that there are no a priori links between colour properties and colour experiences or judgements. This way of picking out colour properties relies on reference-fixing synthetic truths about colours, and these truths (such as, that red is the property that causes red experiences) are not held to express meaning equivalencies. For example, Armstrong claims one must cut "all logical links between colours and what happens in the perceivers of colours". ${ }^{12}$ Similarly, Lycan claims:

my sort of property inheres in an object on its own, regardless of how it is picked out or identified by me or anyone else, regardless of its ever producing sensations in anyone (or being detected by any being at all), and surprisingly, regardless of its actually constituting a disposition to produce sensations in anything. For in principle, it can be specified or defined independently of its doing any of these things. It is as it is, whether or not anyone identifies it or refers to it, whether or not it ever produces sensations of any sort, whether or not it constitutes any disposition, and even if none of these were true. ${ }^{13}$ 
Colour words, such as 'red' and 'blue', are taken to designate rigidly those physical properties of objects that are identified with colour properties. Colour words refer to those physical properties, even in a possible world where those properties bear no relationship to human (or to any) perceivers. Colour properties have only contingent, a posteriori links to our colour judgements and experiences. This view is required by the representationalist in order to provide a noncircular account of colour experience.

It is generally accepted by most physicalists that the physical properties identified with the colours will not form natural kinds or genuine universals. The properties in question are likely to be highly disjunctive micro-physical properties. Some representationalists hazard a guess that colour properties will turn out to be types of surface spectral reflectances (SSRs) of objects. An SSR is specified by the percentage of light the object reflects for every wavelength in the visible spectrum. ${ }^{14}$

If we call the objective physical property identified with the colour red $P r$, then the representationalist will provide the following account of experiences that have the phenomenal character associated with seeming to see red things: all and only such experiences represent $P r$.

\section{Experiences of novel colours}

I will now recount the nature of the experiment that was carried out by Crane and Piantanida, in which they reported that people claimed to see colours that they had never seen before. Prior to this, however, and so that this experiment might be understood more fully, I will relate one other experiment, together with some modern colour theory.

We can consider colours in terms of their location in a space of relations known as the colour space. Such spaces are constructed in virtue of the resemblances that are noted between colours. There are many geometrical representations of the relations that compose the colour space that are not incompatible. The most well-known one is the colour sphere and it reflects some well-established views on the relations between the colours.

All colours on the same horizontal plane have the same lightness or brightness. The properties of the colour sphere have been to some extent explained by reference to the details of the physiology of our visual system. There are two pairs of chromatic detectors working as opponent processors in the brain. For convenience we can think of these as a redgreen detector and a yellow-blue detector. Detection of the light reflected by red objects is at the expense of detection of the light reflected from green objects, and detection of the light reflected from blue objects is at the expense of the light reflected from yellow objects (supposing these 


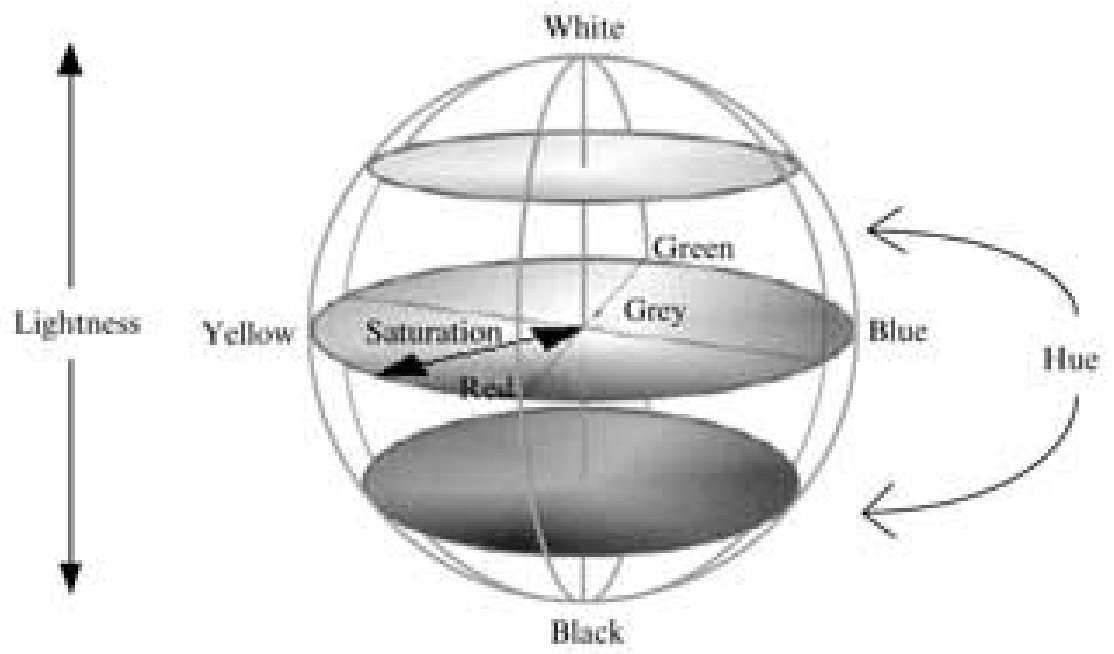

objects are in standard viewing conditions). This appears to explain why we do not perceive reddish-green colours and yellowish-blue colours. This is also why red and green appear diametrically opposed on the above colour sphere.

Opponent process theory also helps to explain the difference between unique and binary colours. The unique colours are red, green, yellow and blue. They are said to be unique because it is possible for there to be shades of these colours that do not look as if they contain any other colours. For example, there are shades of red that look neither yellowish nor bluish. All the other colours are binary and always look to be a mixture of other colours. Orange, for example, always looks reddish and yellowish; purple looks reddish and bluish. Opponent process theory helps to explain this because when we see the unique colours, only one opponent processor need register something. When we see a binary colour such as orange, both the red and yellow opponent processors have to be excited.

With this background in place, consider a preliminary experiment, the principles of which will aid the understanding of Crane and Piantanida's experiment. Normally the colours we see objects as having depend to a large extent on the wavelengths of light emitted from those objects. In some situations, however, the colour perceived does not in any way so correspond. It has been noted by many psychologists that an image that is stabilised on the retina fades from view, and the brain then "fills in" the faded region according to the surrounding unstabilised area..$^{15}$ The psychologist Krauskopf, for example, stabilised a green disk on subjects' retinas. This disk was surrounded by an unstabilised orange area. At first the subjects reported seeing a green disk on an orange background, but 
within several seconds reported that the green disk faded from view to be replaced by a uniformly orange surface. When retinal cells receive no change in the information that they detect, they cease to respond. The device used to stabilise an image on the retina is called an eye-tracker. It is important to note that what gets "filled in" depends on the area surrounding the stabilised area. A similar, but not quite so prominent, effect can be seen by fixating one's eyes in the centre of a green disk on an expansive, uniform orange background. After a time, the green disk fades from view and is "filled in" with orange.

Crane and Piantanida decided to carry out a filling in experiment. They presented subjects with joining red and green areas, as in the diagram below. They ensured that the boundary between the two colours was stabilised on the subjects' retinas (the area indicated by hatched markings below), while the outer portions of the areas of colour were not stabilised.

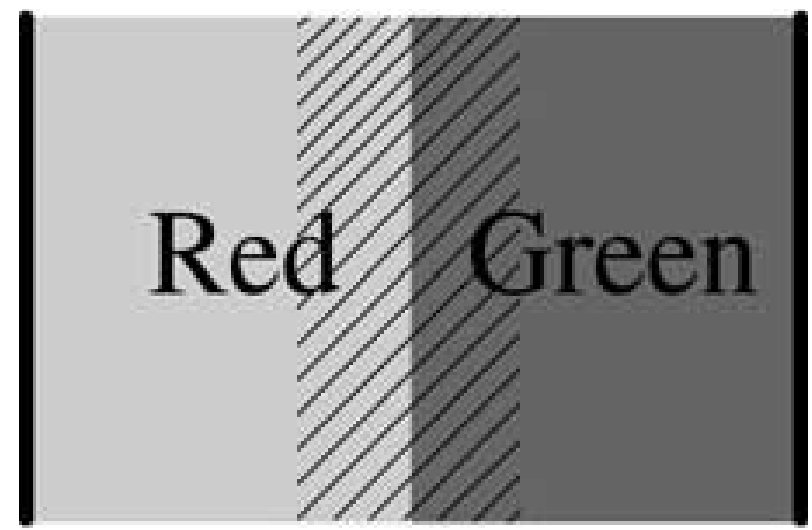

The thought behind the experiment was that the area that was to be "filled in" was surrounded not by one colour, but by two opposing colours, therefore providing conflicting information to the brain, when it tried to "fill in" the area corresponding to the stabilised part of the image. Observers of the image reported different things that they saw in the stabilised area, which fell into the following three categories:

(1) The entire field was covered in a regular array of very small (just resolvable) red and green dots;

(2) The field contained either islands of red on a green background or vice versa;

(3) The field contained a novel hue that subjects reported never having seen before. 
The experiment was repeated with a blue and yellow stimolus, with corresponding results.

The response that is of interest to us is the third one. Here is a quote from Crane and Piantanida, which describes that response further:

some observers indicated that although they were aware that what they were viewing was a color (that is, the field was not achromatic), they were unable to name or describe the color. One of these observers was an artist with a large color vocabulary. ${ }^{16}$

Other observers of the novel hues described the first stimulus as a reddish-green.

Such results appear in conflict with the opponent-process model of colour vision, which predicts that one cannot have experiences of reddishgreens, because when responding to redness, one is simultaneously responding negatively to green. However, Crane and Piantanida speculate that the opponent-process model applies only in cases where the retina is stimulated by light and not to those cases that involve the filling in phenomenon, where the retina is not stimulated. They believe that the filling in phenomenon results from purely cortical activity unrestrained by lower-level retinal-cortico processes that display opponency. In other words, experiences of colour produced by the filling in phenomenon are not restricted to opponent channels and can thus can appear reddishgreen or yellowish-blue.

\section{Why novel colours are a counter-example to representationalism}

If one can have experiences of novel hues such as reddish-green, these threaten the representationalists' account of phenomenal character. To explain why, consider again the account of red and experiences of red that the representationalists' would give. Experiences with the phenomenal character typically associated with redness represent that objective physical property which red objects share. But how does one go about determining whether there is such a property or what property that is? Recall that the first step was to identify red objects with reference to normal perceivers in standard conditions. The second step was to identify the physical property that all those objects had in common.

Turning now to try to give the same account of reddish-green experiences, one faces an immediate difficulty. There are no reddish-green objects that can be identified by normal perceivers in standard conditions. Experiences of reddish-green are illusory. The stimulus used to produce reddish-green experiences is half red and half green. One can make it 
look reddish-green using an eye-tracker, but the stimulus remains half red and half green. Moreover, we know that because our visual system detects colours on the opponent-process model, there could be no object (at least in our world) that looked reddish-green, whatever combination of physical properties it had, unless we viewed it in non-standard conditions. Our best judgements yield the conclusion that there are no reddish-green objects. If there are no reddish-green objects, then how can we be assured that reddish-green is an objective physical property that experiences can represent?

It would be tempting at this point to admit that experiences of reddishgreen are counterexamples to the representationalists' theory. One might hold that reddish-green is a subjective property because no objects are reddish-green. In this case we cannot give a non-circular account of the phenomenal character of reddish-green experiences by saying that it is identical with that property which these experiences represent.

Thus, in order to defend their position and provide an account of the phenomenal character of reddish-green experiences, representationalists have to come up with a plausible account of what objective property experiences of reddish-green represent. It is my contention that there is no plausible candidate. I will try to show this by considering what I hope to be an exhaustive list of prima facie plausible candidates, and show why none of them is acceptable.

\section{Representationalist responses}

\subsection{REDDISH-GREEN IS A PHYSICAL, OBJECTIVE PROPERTY OF SOME OBJECTS OF PERCEPTION}

One response the representationalist might give is to claim that although standard perceivers in standard conditions would never judge an object to be reddish-green, this does not mean that there are no reddish-green objects. The representationalist might hold this on the grounds that colour properties are perceiver independent, and constitute colour properties regardless of whether anyone ever judges them to be so. (This would be in line with the objective physicalism about colours that they must endorse.) The idea would be that there is a physical property identical with reddish-green, despite the fact that this property does not normally cause us to have experiences of reddish-green.

This response does not work. A preliminary problem is that it is not clear what would in fact motivate a choice of colour properties if we do not rely on our best judgements of colour properties, for the physical properties associated with colour are highly disjunctive. David Hilbert, a physicalist, backs this conclusion thus: 
Since colour is a property that is typically discussed only in the context of the interactions of human beings and other kinds of living things with their environment we cannot look to the physical sciences to help us motivate the identification of a property with colour. If there were no living organisms there would be little need to talk of colour in describing and explaining what goes on. Colours that cannot be seen using colour vision are plausibly not colors at all. ${ }^{17}$

This actual problem is not decisive, however, for colour science might one day reveal that objects possess certain properties that affect how they reflect light, and these properties could fall into certain natural groupings. In this case, perhaps one might identify colours with those properties, irrespective of their bearing any strong relations to our colour judgements. ${ }^{18}$

So say that, for whatever reason, an objective physicalist identified reddish-green with the physical property P. Could our experiences of reddish-green not represent $\mathrm{P}$ ? The answer is that they could not, given the kinds of naturalistic accounts of representation that are promoted by the representationalists. I will illustrate this point with regard to Fred Dretske's and Michael Tye's theories. ${ }^{19}$

Recall Dretske's account first. An experience E will represent that $\mathrm{P}$ if and only if it has the function of providing information about $\mathrm{P}$, which it has gained from its evolutionary history. Because the human colour detection system evolved as an opponent system, there is good reason to think that humans could not and did not detect $\mathrm{P}$ until a way of by-passing the opponent channels was invented. If reddish-green experiences were first had in the 1980s, and can be produced only with equipment invented in the last forty years, it would be exceedingly implausible to think that evolution had selected this experience for some adaptive advantage.

However, Dretske allows that some experiences may have implicit functions in virtue of being part of a system, some of whose states have been given explicit functions by evolution. The example Dretske uses to illustrate this is that if we put a " 12 " on an otherwise numberless clock face all the other hand positions now acquire an implicit function to indicate the time. Perhaps, by analogy, one might hold that normal colour experiences have explicit functions to represent and this novel colour experience gains an implicit function in virtue of being part of this system.

To reply to this response, I draw on an argument put forward by William Seager. ${ }^{20} \mathrm{He}$ argues that in order to show that a state has an implicit function in virtue of being part of a system that has some explicit function, one must show that the state does not just accidentally provide information. For example, imagine a speedometer built to represent speeds between 20 and 40 miles per hour. If the pointer positions at 20 and 40 
miles per hour are marked then the pointer positions in-between will have implicit functions to represent speeds in-between. Imagine that this speedometer is not designed to provide information about speeds below 20 miles per hour and that the pointer jumps around erratically until 20 miles per hour is reached. Nonetheless, suppose that an accidental feature of this speedometer is that there is a position where the pointer points when and only when the speed is 10 miles per hour. Seager argues that obviously the speedometer does not have the function of indicating 10 miles per hour even though it carries information about that speed. This is because it is a mere accident that it carries this information. In the case of experiential representation, Seager urges that if one holds that an experience has an implicit function in virtue of belonging to a system that has some explicit function, one should be able to explain the evolutionary advantage of having such an implicit function, to demonstrate that information is not just being carried accidentally.

To return to the case of reddish-green experiences, I would argue that it is an accidental feature of the colour perceptual system that such experiences provide information about a physical property (if indeed they $\mathrm{do}^{21}$ ). There is no plausible evolutionary story to tell about the selective advantage of being able to detect reddish-green only when wearing an eye-tracker.

Now consider Tye's account. He claims that an experience will represent $\mathrm{P}$ if and only if it is caused by and covaries with $\mathrm{P}$, in optimal conditions. We should note straightaway that reddish-green experiences may be caused by and covary with $\mathrm{P}$ when wearing an eye-tracker, but they do not do so otherwise. Because these conditions are not the optimal conditions for viewing colour, the idea that reddish-green experiences represent property P looks suspect.

Perhaps a representationalist might reply that we should not think of reddish-green as a colour property, or at least not as a normal colour property. Thus, perhaps optimal conditions for viewing reddish-green should not be taken to be those for viewing ordinary colours. Say that a representationalist held that reddish-green experiences represented some property $\mathrm{P}$ of a stimulus that was half red and half green. Many properties of objects can only be seen under peculiar conditions. For example, some aspects of the surface structure of a material may only be seen under a microscope. Optimal conditions for viewing these properties will be those in which the object is magnified. The representationalist could hold that when wearing an eye-tracker, one is in optimal conditions for seeing reddish-green, and in these circumstances one's experience would be caused by and covary with $P$.

There are two related responses to this suggestion. The first is to question whether wearing an eye-tracker really is the optimal condition for seeing reddish-green. Not all people saw reddish-green under these 
circumstances, therefore it is plausible that there is no optimal condition. The second and best response is that the optimal conditions specified here are $a d$ hoc. They are chosen only to account for this particular experience. Compare the special conditions required to see other properties. In order to view very small things we need to magnify them. This is not ad hoc because it applies to anything small. Moreover, we can explain why we don't normally see small things because of the eye's limited resolution. Thus, one can build these specific viewing conditions into the general optimal viewing conditions for objects and properties. For example, optimal conditions for seeing must be such that what is seen must reflect a sufficiently large area of light onto the retina. This would also explain why some properties of large objects at a distance are not seen. If optimal conditions for seeing reddish-green are too specific and detailed, and cannot be related to general requirements for seeing, then the charge - that optimal conditions for seeing reddish-green are simply gerrymandered - sticks. To explain what reddish-green experiences represent, the representationalist should not rely solely on the existence of that experience to provide conditions for representation. Some independent grip of optimal conditions is required, and I believe this cannot be had.

Thus, one should not hold that there are reddish-green objects in our world, the physical properties of which can be represented in experience. However, this conclusion appears to suggest another defence that the representationalist might adopt. Perhaps they could claim that although there are no reddish-green objects, this is a contingent fact. Perhaps it is possible that there could be reddish-green objects and perhaps what our experiences represent are the physical properties that such objects would have. I will now consider just this proposal.

\subsection{REDDISH-GREEN OBJECTS AS POSSIBLE OBJECTS}

Could there be another possible world in which objects were reddishgreen? Two reasons for thinking that there could be spring to mind. The first is that we can imagine a planet where there are creatures with a different physiology from ours. If their visual system did not work using opponent processors, then perhaps some objects would look reddishgreen to them. A second reason is that we could imagine a planet where there are different laws of physics. Perhaps in this world, there are reddish-green looking objects because things look coloured in virtue of very different physical properties from our world.

Unfortunately for the representationalist, possible worlds cannot be invoked to explain what reddish-green experiences represent. This is because, on an objective physicalist theory, once we have singled out 
the physical properties that in our world are responsible for colour, those physical properties are the colour properties in all possible worlds. Colour words are taken to refer rigidly to the physical properties so identified, and thus in other possible worlds, the judgements of any perceiver are irrelevant to the identity of the colours. ${ }^{22}$ It is crucial to the objectivity of the theory that colour words rigidly refer in this way and that the logical independence of colour properties from colour experiences is maintained.

This interpretation of objective physicalism is backed up by C. L. Hardin. He says that objective physical properties identified with colour properties "would constitute the colours in a possible world in which they did not bear the causal relationships to human perceptual systems that they bear in the actual world". ${ }^{23}$ The same would hold for any sentient creature. Byrne and Hilbert, who are physicalists, suggest that the best description of a world with a very different physics from our own is that in such a world objects merely look coloured. ${ }^{24}$

To summarise, for an objective physicalist the judgement that an object looks reddish-green made in a possible world other than our own is irrelevant to establishing the physical identity of reddish-green. Thus the representationalist cannot appeal to other possible worlds to establish what reddish-green experiences represent.

\subsection{REDDISH-GREEN AS AN INTENTIONAL INEXISTENT}

If a representationalist cannot appeal to possible worlds to explain what it is that reddish-green experiences represent, could they not claim that reddish-green experiences represent reddish-green "intentional inexistents"? ${ }^{25}$ In his latest book, Michael Tye has claimed that we can think of after-images as intentional inexistents - as unreal, intentional objects. ${ }^{26}$ His idea is that after-images are always illusory, in the sense that there is no coloured patch existing in objective physical space where we seem to see the coloured patch. A coloured patch is represented to exist, but there is no such coloured patch. Yet, one can appreciate that one is having an experience of an after-image and realise that it does not exist in public space. In virtue of these features, Tye calls after-images intentional inexistents.

One might think that experiences of reddish-green were experiences of intentional inexistents because such experiences would always be illusory in the same way as after-images. One could also easily appreciate that one was having such an illusory experience and that the colour that seemed to be before one did not exist. Moreover, even if reddish-green objects were impossible objects, there is no requirement that intentional inexistents must be possible objects. Why can a representationalist not 
say that reddish-green experiences represented a reddish-green intentional inexistent?

The reason why they cannot is that most representationalists want to provide a naturalistic account of representation..$^{27}$ In fact, most modern representationalists are representationalists because they believe that by claiming that phenomenal character is a kind of content, and by providing a naturalistic account of that content, they can naturalise phenomenal character. We saw previously that Tye and Dretske offered causal covariation and teleological accounts of content. These accounts postulated that states had contents in virtue of naturalistic relations (such as causation) which they bore to unproblematically naturalistic objects (such as physical objects). For example, on Tye's theory a state only has to be such that it would be caused by and covary with something in optimal conditions for it to represent that thing. If one says that a state represents an intentional inexistent, then this type of naturalistic account of representation is not open to one. As Tim Crane says, a naturalistic theory of content requires:

a specification in non-intentional terms of the conditions under which an intentional state has the intentional contents that it does, or concerns the object(s) it does. ${ }^{28}$

Intentional inexistents are not unproblematically naturalistic objects, nor does an explanation that contains them feature only non-intentional terms. Moreover, what kind of relations a state could bear to such an object in order for it to represent it is unclear. It is certainly not clear that they could be relations permissible by any form of naturalism. In short, insofar as a representationalist wishes to provide a naturalistic theory of representation then they should resist recourse to intentional inexistents.

One question remains to be answered in this section. If what I have said is right, then why does Tye, who is avowedly naturalist, talk of intentional inexistents? Firstly, one should note that Tye only mentions in passing in a footnote that we might regard after-images as intentional inexistents (and he adds that he need not quantify over intentional inexistents). Moreover, in a later footnote in the same chapter, he makes it clear that this explanation is not part of his official view for a variety of reasons. ${ }^{29}$ Indeed, when we look more closely at Tye's account of after-images, we can see that a reddish-green after-image would still pose a problem for Tye in a way that an after-image of red, for example, would not. This is because the intentional inexistent - the unreal object does no explanatory work for Tye at a level that is supposed to explain phenomenal character. I will now show why this is so.

According to Tye, when one has an experience of a red after-image, one's experience represents redness. Tye says that although the experience 
represents something unreal, it is still the case that "redness enters into the content of the experience". ${ }^{30}$ Indeed, Tye thinks that to the extent that content concerning the unreality of the object enters the experience, it only does so only in a sense of experience "broadly understood". ${ }^{31}$ Tye makes it clear that the content pertaining to the unreality of the object does not affect the phenomenal character of the experience - the content pertaining to unreality is more like a judgement about the experience rather than part of the experience proper. ${ }^{32}$ Thus, Tye holds that when seeing a red after-image, redness enters the content of the experience proper. As we have seen already, Tye holds a causal covariation theory of the content of experience (but only of that content that affects phenomenal character ${ }^{33}$ ) It is open to Tye, therefore, to provide a naturalistic account of content pertaining to redness on the causal covariation theory, and hence to claim to have naturalised phenomenal character. An experience would have such a content if, in optimal conditions, it would covary with red things. But now we can see that a parallel account is not open to Tye in the case of reddish-green. If an experience represents a reddish-green intentional inexistent, then the experience proper would have to contain content pertaining to reddish-green. As we have seen in previous sections, the causal covariation theory cannot account for a colour property that does not, or could not, exist.

In conclusion, a representationalist could say that reddish-green experiences represent reddish-green intentional inexistents. However, the explanatory benefits of such a move are highly dubious, and are certainly exceedingly problematic if one is looking to provide a naturalistic account of experiences and their phenomenal character. Tye introduces talk of intentional inexistents, not to explain representation responsible for phenomenal character, but rather to explain the fact that one can appreciate or judge that after-images do not exist, while one seems to see them.

\subsection{REDDISH-GREEN AS A REPRESENTATION OF RED AND GREEN}

I will now consider an altogether different reply that the representationalist might make. A representationalist might claim that reddish-green experiences in some sense represent that both the properties red and green inhere in an object. How might one interpret such a claim?

One way that it might be taken is as the claim that the object is represented to be both red and green all over at the same time. It might be thought that an object could be represented as being red all over and green all over at the same time, despite the fact that no object could be so. This thought could be backed up by noting that experiences can represent physical impossibilities. Pictures of impossible objects might be thought to yield such experiences. 


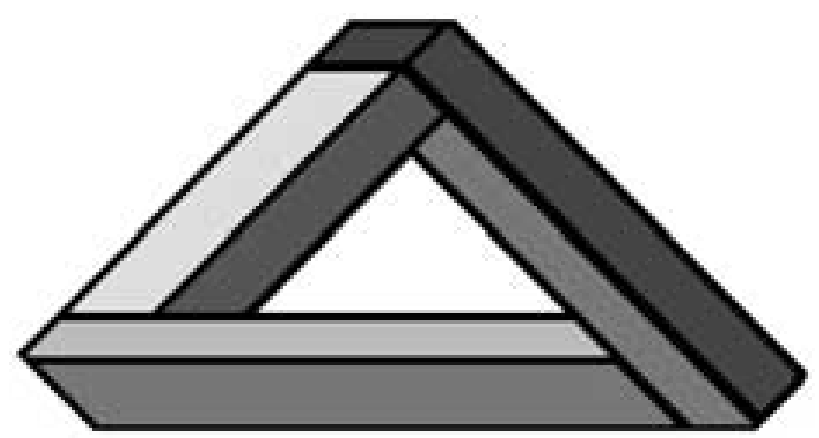

This attempt to account for reddish-green experiences is, however, a poor one for it fails to account for the subject's reports of the phenomenal character of their experiences of reddish-green. Subjects do not report that they see the stabilised area as being both red and green at the same time. What they report is a novel binary colour that looks similar to both red and green. Consider the following description by Crane and Piantanida:

The appearance of the field can best be described by using an analogy to colors that can be perceived under normal viewing conditions. An observer viewing a field composed of an additive mixture of red and blue light such that the proportion of red and blue light varies across the field - from strongly red on the left side of the field to strongly blue at the right side of the field ... might describe the field as lavender near the blue edge, purple in the middle and magenta near the red edge ... This analogy is a good description of the field seen by those observers who describe the stabilized field as simultaneously red and green, although greener near the unstabilized green boundary and redder near the unstabilized red boundary. ${ }^{34}$

Thus, subjects describe their experience as similar to other binary colours, and this is supported by their reports of the variation of hue across the stabilised region.

An ordinary binary colour, such as orange, is not a combination of two properties, namely yellow and red. No self-respecting representationalist takes orange experiences to represent red and yellow at the same time. Here, for example is what Byrne and Hilbert say:

Take orange. We say it is a binary colour because it is, or appears to be, a mixture of red and yellow. But what does that mean? Is orange a combination of the two properties red and yellow? No: a 'combination' of two properties A and B is presumably the property A\&B (if it's not that, then what?). Everything that has the property red\&yellow is red, but (many) orange objects are not red. ${ }^{35}$

If reddish-green is seen as a binary colour, as the evidence suggests, then it is implausible to suggest that reddish-green experiences represent that surface as being both red and green. 
Perhaps one might read the claim that reddish-green experiences represent that both red and green inhere in an object slightly differently. To help us here, consider what accounts representationalists give of why binary colours look similar to two unique colours. There are two such accounts. Michael Tye suggests that the binary distinction can be accounted for simply as a truth about colour mixing. Orange is the colour one gets when one mixes red and yellow pigment, but red is not obtained from mixing purple and yellow. ${ }^{36}$ This account would not help here for we know that reddish-green is not the colour one gets when red and green pigment. Moreover, not all truths about the "non-novel" unique and binaries can be accounted for in this way. For example, green can be obtained from a mixture of yellow and blue pigment, but green is not a binary colour. This suggests this account should be abandoned.

The second and more plausible account is given by Byrne and Hilbert. Firstly, they distinguish between colours and hues. A particular uniformly coloured object will look to have a certain colour, say red, but it will also look to be a determinate hue of red, say $\operatorname{red}_{21}$. Hues stand to colours as determinates to determinables, and thus as pigeons stand to birds and birds to animals. They claim an experience of red $_{21}$ will represent both the hue $\operatorname{red}_{21}$ and the colour red. They also claim that properties such as "reddishness" can be represented in experience. This is the property of being either red-or-orange-or-purple. Experiences of orange objects will represent both the properties reddishness and yellowishness, while experiences of red will represent only reddishness.

Could we adapt this account for reddish-green experiences? Do they represent the properties reddishness and greenishness? Well, suppose that they do. This will not solve the problem of just what these experiences represent. According to Byrne and Hilbert an experience of a particular shade of red, say red ${ }_{21}$, will represent: $\operatorname{red}_{21}$, red and reddishness. Similarly a particular shade of orange, say orange ${ }_{45}$, will represent: orange ${ }_{45}$, orange, reddishness and yellowishness. What of a reddish-green experience? It may represent reddishness and greenishness, but we have not yet found determinates for the particular hues that these experiences represent. We need to find such determinates because the experiences of reddish-green varied from more reddish to less reddish. The experience consisted in particular hues of reddish-green. All we have succeeded in doing is explaining the binary nature of reddish-green. We have not yet found properties that experiences of particular reddish-green hues represent. Thus, this attempt to account for the phenomenal character of reddish-green experiences is incomplete.

One should also note that one who follows the Byrne-Hilbert proposal cannot circumvent this problem of accounting for determinate hues by saying that a particular reddish-green experience represents, say, forty per cent reddishness and sixty per cent greenishness. Reddishness and 
greenishness are physical properties. Reddishness is that physical property that objects that are red-or-orange-or-purple share. Such properties are an all-or-nothing affair. For the same reason that an object cannot be forty per cent square or represented to be forty per cent square, an object cannot have forty per cent reddishness. Thus, one cannot fully account for particular reddish-green hues by claiming that they in some sense represent both reddishness and greenishness.

\section{A diagnosis}

I have tried to show that no plausible candidate can be found for what objective physical colour property reddish-green experiences represent. I have argued that there are no reddish-green objects in this world. Moreover, even if there were, the kind of naturalistic theories of representation the representationalists advocate would prevent them from being able to hold that our experiences represented such a property. I have also shown that considerations of possible worlds are irrelevant in establishing the physical identity of colour if one is an objectivist and I showed that a naturalist should not resort to intentional inexistents to explain phenomenal character. Lastly, I considered trying to account for reddish-green experiences by holding that in some sense they represented both red and green. I argued that such attempts fail. Thus reddish-green experiences constitute a counterexample to naturalistic representational theories.

One way to see clearly the nature of the problem for the representationalist is to think about the experiences of novel colours had by the subjects in the experiment. The subjects reported that the surface in front of them appeared to be reddish-green. One might think that this is ground enough to say that the subject's experience represented the surface in front of them as having a reddish-green property. Certainly, in some cases when we say experiences are representational we merely wish to capture the fact that the experience represents the world to be a certain way, together with the transparency of this experience. However, the representationalists under consideration have to ensure that the properties represented in experience are objective properties that can be defined independently of experience, and this is where the problem lies.

If one accepts that a real problem has been identified, then one might think that experiences are representational but hold that one cannot give a full and noncircular account of experience just in virtue of an appeal to what they represent. Alternatively, one might think that reddish-green is not a property or possible property that is represented but merely an example of a non-representational phenomenal property of experience. 
Faced with this counterexample, a representationalist could do one of two things. They may continue to seek an objective property that reddish-green experiences represent. I hope to have made plausible the case for thinking this cannot be done. Secondly, a representationalist might directly question Crane and Piantanida's results. It should be noted that Crane and Piantanida's experiment has been carried out only once. Although it was reported in Science, a well-respected journal, the representationalist might argue that they do not have to take the results of such an experiment seriously until the results are repeated. Moreover, not all subjects of the experiment reported having a novel experience. On these grounds some representationalists might dispute the experimental paradigm and the reports of its subjects.

These concerns about the experiment in question appear reasonably grounded, but I do not believe that they ultimately undermine the force of the example. To explain why, I will firstly address the question of whether it is reasonable to conclude that if subjects undergo a novel experience as in the experiment, the experience is a novel experience of colour. Secondly, I will address some more general worries concerning the experiment.

Three contemporary authors discuss novel colours, namely, Hardin, Thompson and Westphal. ${ }^{37}$ They are primarily concerned with the question of whether alleged experiences of novel colours could be considered to be colour experiences. Thompson and Hardin agree that novel experiences, such as reddish-green, would be colour experiences. (Hardin is an eliminativist about colour properties, but agrees with Thompson that reddish-green experiences are colour experiences.) Westphal disagrees and argues that there could not be novel colour experiences.

Both parties in this debate are agreed on what would decide whether a novel experience was an experience of colour. Recall the colour space that represented the resemblance relations among the colours as experienced. It is difficult to know which of these relations are necessary or essential to the colours being the colours that they are. Hardin, for example, says that the number of just noticeable differences between unique red and unique yellow are not essential to them, but that there is some path of hue resemblance between them might be thought to be necessary. ${ }^{38}$ Similarly, that orange lies between yellow and red might be thought to be essential to orange being orange. Another necessary proposition might be that all saturated colours must have a hue and a lightness. ${ }^{39}$ What the two sides in the debate are agreed upon is that if a purported novel hue really is a colour then it must find a place in colour space. Thus, if a novel experience is a novel experience of colour, there must be a resemblance between the novel experience and other experiences of colour and this resemblance must be of the kind that non-novel colour experiences bear to each other. 
Westphal claims that any alleged novel hue could not find a place in our colour space and thus that there can be no novel colours:

It is possible ... to show that the insertion of a fictitious colour into our three dimensional colour space will disrupt the order and prevent us from conceiving some other colour or group of colours in the space, independently of the explanation of this fact in the generative basis of the space. For colours and the similarity colour space are inseparable. The positions of the colours on the hue circuit, for example, are determined by the positions of their intermediaries and vice versa, and these together determine the geometry of the space. ${ }^{40}$

In response to this, Thompson argues that while no other colours could be inserted into the familiar three-dimensional colour space, they could be fitted into a four-dimensional colour space that contained the threedimensional space.

Settling the issue between Thompson and Westphal would entail deciding whether extensions to the colour geometry such as this are permissible. I can think of no good reason why an extension like the one suggested, which encompasses the original geometry and leaves its internal relations intact, should not be permitted. We should allow that the frequently alleged a priori phenomenal exclusivity of red and green could be challenged on empirical grounds. Further, if our experience is really a colour experience, then this would suggest that at least some colours are not physical properties of objects and must be defined by reference to the phenomenal characters of the experiences that are associated with them.

In any case, even if the experiences in question are not colour experiences, the question of what property is represented by these novel experiences still remains for the representationalist. The novel experiences elicited in Crane and Piantanida's experiment seemed to represent some property of the surfaces of objects. If the representationalist is to give an account of this property (colour or not) it must be specified in objective terms (to prevent circularity) and, given that it is a property of the surfaces of objects, it should also be specified in physicalist terms (given the naturalism of the representationalists). ${ }^{41}$ Thus the arguments against the representationalist above still hold. Whether we classify this experience as one of colour or not is irrelevant to the experience providing a counterexample to representationalism.

Turning now to a potentially more worrying criticism of this counterexample, a representationalist could dispute Crane and Piantanida's experimental paradigm or the reports of the subjects, with a view to claiming that a novel experience was not elicited at all. There are anecdotal reports that question whether a genuinely novel experience was had at all. ${ }^{42}$ If the experimental result proved false, would the representationalists still have a case to answer? 
I think the answer is clearly yes. The reason is that Crane and Piantanida's experiment strongly suggests that there is a metaphysical possibility that we could elicit a novel experience in a subject, through by-passing the normal way sensory or experiential information is processed in the brain. Consider again Crane and Piantanida's explanation of why novel experiences could be elicited by the eye-tracker. They held that normal colour experiences are subject to opponent channels, while filling in involves high-level cortical processes not subject to opponency. It seems clearly possible that a creature could have developed a visual system that did work by opponent processes at lower levels and that this could be bypassed in some way (perhaps by direct stimulation of the brain) to elicit a novel experience. Indeed, it appears feasible that there could be a number of different possible ways the brain could work, which would allow for eliciting novel experiences of the kind imagined here. Further, it is quite possible that these experiences do not represent anything in the creature's environment as they do not, and could not, stand to any property in any of the required relations that a naturalistic representationalist specifies as those required for representation to occur. Therefore, even if Crane and Piantanida's experimental results proved unfounded, the metaphysical possibility of such experiences remains. Thus, I hold that novel colours are a counterexample to representationalism. ${ }^{43}$

Department of Logic and Metaphysics, University of St. Andrews

\section{NOTES}

${ }^{1}$ See Nagel (1974).

${ }^{2}$ See particularly Tye (1995) pp. $135-137$ and Dretske (1995) chapter 2 . This consideration is also put forward by Harman (1990) and Lycan (1996) in favour of their versions of representationalism. The point has been noted about experience generally by Moore (1922) p. 22, McGinn (1982) p. 13, and Shoemaker (1996) chapter 5.

3 Many philosophers of mind (not just representationalists) are rather hesitant about spelling out what it is to be a naturalist. I suggest that it amounts to having a desire to give an explanation of the nature of the mind while only positing ordinary familiar physical objects and the relations that we suppose these objects bear to each other - such as spatial and temporal relations and relations of identity and causation. In particular, the desire is to provide a theory that does not have to posit distinctively mental entities or forces. Moreover, there often seems to be a commitment to finding explanations that relate what might otherwise be taken to be independent domains of discourse, such as the personal and subpersonal or the intentional and the physical.

${ }^{4}$ Of course, one question to ask about such theories would be how one specifies what normal perceivers and normal conditions are, but this question is not relevant to my concerns here.

${ }^{5}$ See Byrne and Hilbert (1997a) pp. xxii-xxiii for a clear account of the difference between subjectivism, objectivism and physicalism about colour. One should note that Hardin (1988) 
promotes an eliminativist view according to which there are no colours - he is therefore not a subjectivist (nor an objectivist). Hardin claims "We are to be eliminativists with respect to colour as a property of objects" (p. 112). At the same time he claims that subjectivists hold that "although colours are indeed features of material objects, they are so only as dispositions of those objects to affect organisms in an appropriate sensory fashion under the proper circumstances" (p. 59).

${ }^{6}$ Locke (1690) is often cited as holding the former main-stream dispositionalist view, while Jackson and Pargetter (1997) hold that colours are the categorical bases of dispositions to look coloured (moreover they suppose the categorical bases will be physical properties of objects).

7 Tye (1995) p. 144. See also Dretske (1995) and Byrne and Hilbert (1997b).

${ }^{8}$ Tye (1995) p. 145.

${ }^{9}$ Dretske (1995) p. 93.

${ }^{10}$ Because the representationalists are naturalists they adopt this physicalist line. It is possible to be an objectivist but hold that colour properties are objective, nonphysical properties of objects, but I will not consider this view here. James Cornman (1975) adopts this objectivist, nonphysicalist line. It is outlined in Hardin (1988) pp. 60-61. The main problem with the view is that either such properties are causally connected to the physical and have physical effects or they do not. If the former is the case, then one should be able to test for such properties by physical means and add them to one's physical theory. If the latter is the case, then either they are epiphenomena or they cause only mental (nonphysical) effects. The former option appears to render them physical properties, the latter is plausibly non-naturalistic and unattractive.

${ }^{11}$ Lycan (1996) p. 74. By an Armstrongian colour property, he means an objective physical colour property. Shepard's normal viewing conditions are specified in evolutionary and ecological terms, roughly, those that existed on the Earth's surface when colour vision was evolving.

${ }^{12}$ Armstrong (1997) p. 45, fn. 13.

${ }_{13}$ Lycan (1996) pp. 73-74.

14 Tye (1995) and Byrne and Hilbert (1997b) suggest this.

15 See, for example, Krauskopf (1963) pp. 741-743 and Yarbus (1967).

16 Crane and Piantanida (1983) p. 1079.

17 Hilbert (1992) pp. 358-359.

${ }_{18}$ Note that if such a strategy were adopted to account for colours (and reddish-green in particular) then either it could turn out that some of our colour judgements are fundamentally mistaken (some objects, which in ideal conditions we judge to be pink, could turn out to be reddish-green), or alternatively it could turn out that some objects have two colours - they are both pink and reddish-green. Although this may be seen by some to be an unattractive and unintuitive consequence of this view, an objective physicalist could embrace such a possibility. I do not wish to reject representationalism on the grounds that it must hold an objective physicalist view of colour. My argumentative strategy here is not to reject objective physicalism, but instead to show that if it were true and combined with representationalism, not all experiences can be accounted for by representationalism.

${ }^{19}$ Of representationalists with naturalistic aspirations, Dretske (1995) and Tye (1995) provide the most detailed accounts of the theories of representation they proscribe. Other representationalist usually gesture to one or other of these theories. See, for example, Lycan (1996).

${ }^{20}$ Seager (1999) p. 158.

${ }^{21}$ It is not clear that such experiences do carry information about a property on the grounds that, unlike the speedometer indicating 10 miles an hour in the example above, the 
novel experience does not reliably indicate the presence of $\mathrm{P}$ because $\mathrm{P}$ can occur without the relevant experience occurring if you are not wearing an eye-tracker.

${ }^{22}$ In particular, in a world that shared our physics, where the inhabitants judged there to be many more colours than there are in our world, they would have to be mistaken.

${ }^{23}$ Hardin (1988) p. 65.

${ }^{24}$ Byrne and Hilbert (1997b) p. 282, fn. 8. I think that Byrne and Hilbert are right in this regard. However, even if we were to allow that in a world with a physics very different to our own there could be colours that do not exist in this world, a teleologist or a causal covariation theorist would have difficulty establishing how experiences must relate to merely possible properties in order for those experiences to represent those properties. See the section below on intentional inexistents for an elaboration of a similar point.

${ }^{25}$ I would like to thank an anonymous referee for suggesting this reply.

${ }^{26}$ Tye (2000) p. 96, fn. 15.

${ }^{27}$ In addition to Tye and Dretske, Lycan (1996), Papineau (1993), and Botterill and Carruthers (1999) are representationalists who advocate naturalism.

${ }^{28}$ Crane (2001)

29 Tye (2000) p. 97, fn. 20 and p. 96, fn. 15.

30 Tye (2000) p. 85.

31 Tye (2000) p. 85.

${ }^{32}$ In Tye's terminology, content pertaining to redness affects the phenomenal character of the experience because it is part of the nonconceptual content of experience, while that pertaining to the unreality of the object does not affect the phenomenal character and is conceptual content. (Nonconceptual content is such that a state can have that content while the subject of that state need not possess the concepts required to specify the content. See Peacocke (1992) chapter 3.)

${ }^{33}$ It is interesting to note that Tye does not give a theory of conceptual content. It is notoriously difficult to do so and Tye himself suggests that a causal covariation theory would only account for nonconceptual content that is responsible for phenomenal character. Moreover, it is not open to Tye to claim that reddish-green is conceptual content because he believes that such content has no effect on phenomenal character, and the novel experiences produced by Crane and Piantanida clearly did elicit novel phenomenal character, if they elicited novel experiences at all.

${ }^{34}$ Crane and Piantanida (1983) p. 1079.

${ }_{35}$ Byrne and Hilbert (1997b) p. 280.

36 Tye (1995) p. 148. Byrne and Hilbert (1997b) point out its deficiencies.

${ }^{37}$ Hardin (1988), Thompson (1995), Westphal (1987).

${ }^{38}$ Hardin (1988) pp. 126-127.

${ }^{39}$ See Thompson (1995) pp. 269-271. Note that it was often thought to be necessary that red and green were mutually exclusive colours. Crane and Piantanida's experiment casts doubt on this.

${ }^{40}$ Westphal (1987) pp. 100-101.

${ }^{41}$ Could representationalists claim that what was represented by reddish-green experiences was not a physical property of objects, but a particular brain state? This would, however, sit badly with their claim that visual experiences deliver information about (i.e. represent) the environment, rather than brain states themselves. And it will be a difficult task to show why brain states are not represented as brain states, rather than as states of the environment.

${ }^{42}$ See Hardin (1988) p. xxix.

${ }^{43}$ I would like to thank Alan Millar, Peter Sullivan, José Luis Bermúdez and Agustin Rayo for their comments and for discussion. 


\section{REFERENCES}

Armstrong, D. M. (1997). "Smart and the Secondary Qualities", in A. Byrne and D. R. Hilbert (eds.), Readings on Color Volume 1: The Philosophy of Color. Cambridge, Massachusetts: MIT Press.

Byrne, A. and Hilbert, D. R. (1997a). "Introduction", in A. Byrne and D. R. Hilbert (eds.), Readings on Color Volume 1: The Philosophy of Color. Cambridge, Massachusetts: MIT Press.

Byrne, A. and Hilbert, D. R. (1997b). "Colors and Reflectances", in A. Byrne and D. R. Hilbert (eds.), Readings on Color Volume 1: The Philosophy of Color. Cambridge, Massachusetts: MIT Press.

Botterill, G. and Carruthers, P. (1999). The Philosophy of Psychology. Cambridge: Cambridge University Press.

Cornman, J. (1975). Perception, Common Sense and Science. New Haven: Yale University Press.

Crane, H. D. and Piantanida, T. P. (1983). "On Seeing Reddish Green and Yellowish Blue", Science 221, pp. 1078-1080.

Crane, T. (2001). "Intentionality", Routledge Encyclopedia of Philosophy Online. http:// www.rep.routledge.com/.

Dretske, F. I. (1995). Naturalising the Mind. Cambridge, Massachusetts: MIT Press.

Hardin, C. L. (1988). Color for Philosophers: Unweaving the Rainbow (Expanded Edition). Indianapolis: Hackett.

Harman, G. (1990). "The Intrinsic Quality of Experience", in J. E. Tomberlin (ed.), Philosophical Perspectives 4: Action Theory and Philosophy of Mind. Atascadero: Ridgeview.

Hilbert, D. R. (1992). "What is Color Vision?", Philosophical Studies 63, pp. 351-370.

Jackson, F. and Pargetter, R. (1997). "An Objectivist's Guide to Subjectivism about Colour", in A. Byrne and D. R. Hilbert (eds.), Readings on Color Volume 1: The Philosophy of Color. Cambridge, Massachusetts: MIT Press.

Krauskopf, J. (1963). "Effect of retinal image stabilization in the appearance of heterochromatic targets", Journal of the Optical Society of America 53, pp. 741-743.

Locke, J. (1690/1975). An Essay Concerning Human Understanding, P. Nidditch (ed.), Oxford: Oxford University Press.

Lycan, W. G. (1996). Consciousness and Experience. Cambridge, Massachusetts: MIT Press.

McGinn, C. (1982). The Character of Mind. Oxford: Oxford University Press.

Moore, G. E. (1922). "The Refutation of Idealism", in his Philosophical Studies. London: Routledge and Kegan Paul.

Nagel, T. (1974). "What is it like to be a bat?", Philosophical Review 83, pp. 435-451.

Papineau, D. (1993). Philosophical Naturalism. Oxford: Blackwell.

Peacocke, C. (1992). A Study of Concepts. Cambridge, Massachusetts: MIT Press.

Seager, W. (1999). Theories of Consciousness. London, Routledge.

Shoemaker, S. (1996). The First-Person Perspective and Other Essays. Cambridge: Cambridge University Press.

Thompson, E. (1995). Colour Vision: A Study in Cognitive Science and the Philosophy of Perception. London and New York: Routledge.

Tye, M. (2000). Consciousness, Color and Content. Cambridge, Massachusetts: MIT Press.

Tye, M. (1995). Ten Problems of Consciousness: A Representational Theory of the Phenomenal Mind. Cambridge, Massachusetts: MIT Press.

Westphal, J. (1987). Colour: Some Philosophical Problems from Wittgenstein. Oxford: Basil Blackwell.

Yarbus A. L. (1967). Eye Movements and Vision. Trans. Haigh. New York: Plenum. 